\title{
(Des-re)construindo espaços transgressores e conhecimentos nas aulas de PLA: retratos de uma experiência na Universidade Federal de
}

\author{
Alagoas
}

Rusanil dos Santos Moreira Júnior ${ }^{1}$

\section{Resumo}

Conforme Bakbtin/Volochinov (2014), a lingua, como produto ideológico, reflete e refrata a realidade que lhe é exterior. Partindo desse pressuposto, o objetivo deste artigo é apresentar as análises das discussões sobre quatro fotos captadas por estudantes, que tiveram como tema de seus cliques as cidades urbanas. As fotografias são resultados de uma aula-passeio de Português como Lingua Adicional no Centro da cidade de Maceió, em Alagoas. Para isso, adotei como aporte teórico os estudos sobre Letramento Crítico (MONTE MÓR, 2012; MENEZES DE SOUZA, 2011; JANKS, 2016) e as teorias contemporâneas sobre a globalização e seus efeitos (RIZVI; LINGARD, 2010; CASTRO-GÓMEZ; GROSFOGUEL, 2007). Metodologicamente, considero esta pesquisa como um estudo de caso, numa perspectiva qualitativo-interpretativista de pesquisas em Linguística Aplicada. Como resultado, as análises demonstram uma postura crítica dos participantes em relação às práticas cotidianas raramente questionadas e indicam um relevante aprimoramento de suas habilidades linguístico-discursivas.

Palavras-chave: Fotografias. Cidades urbanas. Letramento crítico. Português como língua adicional. Globalização

\footnotetext{
${ }^{1}$ Professor substituto de Língua Espanhola da Faculdade de Letras da Universidade Federal de Alagoas (Fale/Ufal). Mestre em Linguística, com ênfase em Linguística Aplicada.
} 


\section{(Des-re)construindo espaços transgressores e conhecimentos nas aulas de PLA: retratos de uma experiência na Universidade Federal de Alagoas \\ Rusanil dos Santos Moreira Júnior}

\section{Introdução $^{2}$}

(Des-re)construir práticas não é um movimento novo se pensarmos no estabelecimento, estruturação e organização das sociedades globalizadas, principalmente quando consideramos a revolução tecnológica que assola e conduz as nossas práticas diárias e que, por isso, as transformações lhe são medulares. No entanto, no campo da educação formal, (des-re)construir o espaço da sala de aula e, consequentemente, a práxis docente na produção de formas de saber, pensar e expandir conhecimentos parece ser um esforço complexo e um exercício laborioso de muros ainda resistentes. As origens podem ser diversas, entre elas a carência de incentivos de toda ordem, o amedrontamento à inovação e o apego ao pregresso.

Desde os jesuítas, apesar da aparição e estabelecimento de novos métodos de ensino, a pedagogia tradicional, caracterizada pela preleção verbal e a transmissão verticalizada de conhecimentos, não deixou de ser um dos métodos de ensino mais privilegiados e ainda em voga na educação brasileira em todos os níveis de ensino. Sendo o mais controverso também entre os especialistas (GIL, 2009). No ensino de línguas não maternas das últimas quatro décadas, no Brasil, a abordagem comunicativa, pautada quase que mecanicamente nas quatro habilidades (ler, escrever, ouvir e falar), ainda domina os espaços formais para a aprendizagem de uma língua adicional. Espaços esses que reiteradamente engessam valores, princípios, culturas, formas de ensinar-e-aprender, visões de mundo e verdades. Entre essas verdades, estão as receitas de organização, sequenciação e execução de aulas com uma exacerbada preocupação com o conteúdo linguístico, deixando à margem a importante discussão crítica - não pretextual - sobre as relações de poder (JANKS, 2016) imbricadas nos conhecimentos circulados em sala de aula na vida de quem os está apre(e)ndendo.

Não cabe neste texto e nem é o seu objetivo avaliar se a abordagem comunicativa é ou não a mais adequada para o ensino de línguas, o que viria a desaguar numa lógica binária de entender o mundo (KLEIMAN, 2013). Afinal, todas as abordagens proporcionaram uma relevante contribuição na formação docente de professores de diferentes épocas. Em contrapartida, saliento que a perspectiva transcultural e crítica de ensinar-e-aprender uma

\footnotetext{
${ }^{2}$ Este trabalho é um recorte revisitado da minha dissertação de mestrado Português como lingua adicional $e$ letramento crítico: ensino-aprendizagem com participantes falantes de outras linguas na Universidade Federal de Alagoas, na linha de Linguística Aplicada, defendida em 2016, no Programa de Pós-graduação em Letras e Linguística da Universidade Federal de Alagoas, sob a orientação do Prof. Dr. Sérgio Ifa.
} 
língua na contemporaneidade, a qual pude desenvolver sob a ótica do letramento crítico (doravante LC), é uma forma alternativa que encontrei para (des-re)construir a sala de aula de línguas adicionais. Nela, o aprimoramento das habilidades comunicativas e o desenvolvimento da consciência crítica andam de mãos dadas, em harmonioso diálogo, em razão de que um sem o outro descaracteriza o que hoje defendo e entendo por uma proposta alternativa de ensino-aprendizagem de línguas resistente às práticas colonializantes e estruturalistas.

Nessa direção, este texto relata uma experiência sobre o ensino-aprendizagem de português como língua adicional (PLA) sob a perspectiva do LC, com participantes universitários falantes de outras línguas na Universidade Federal de Alagoas (Ufal), no ano de 2015, em que houve o primeiro curso de PLA no consolidado projeto de extensão Casas de Cultura no Campus (CCC) dessa mesma universidade à comunidade acadêmica. O objetivo do curso era não somente proporcionar o desenvolvimento linguístico-discursivo das habilidades comunicativas dos estudantes, senão também, concomitantemente, promover uma formação crítico-cidadã sobre o que iriam aprender e a realidade que estavam vivenciando no Brasil. Revisitei essa discussão porque creio que é emergente a promulgação de espaços e práticas docentes que transgridam (PENNYCOOK, 2006) os limites do pensamento e as políticas tradicionais, nos quais a sala de aula de línguas busque conciliar-se com as práticas sociais em que seus aprendentes estão expostos dentro e fora dela.

Nesse sentido, a experiência que trago à discussão vem a realçar o rompimento dos paradigmas da sala de aula tradicional, cujo perfil já refletia a própria constituição do grupo de participantes desta pesquisa, visto que esteve composto por estudantes universitários de diferentes países, com formações acadêmicas distintas, com faixas etárias díspares e com habilidades comunicativas heterogêneas de/em língua portuguesa, fatores esses que não impediram o diálogo e aprendizagem ressignificada da/na língua para os participantes envolvidos, entres eles eu, o professor-pesquisador.

Para compreender como se deu esse processo, busquei compreender os elementos constitutivos do processo de ensino-aprendizagem de PLA por meio da identificação e análise deles, que consolidaram um trabalho maior. Contudo, neste texto o meu objetivo é discutir um desses elementos, a imprescindibilidade de ações transgressoras para a aprendiragem do $P L A$, por meio do relato de experiências de um projeto exequível. Ou seja, a importância 
da construção de um ambiente em que, dentro das condições possíveis, formas alternativas de ensinar-e-aprender uma língua sejam germinadas.

A seguir, defino sucintamente as bases teóricas, esclareço o delineamento metodológico e, por fim, exponho a interpretação dos dados apresentados. Em decorrência da dimensão deste texto, abordo concisamente as teorias estudadas e as análises levadas a cabo.

\section{Fundamentação Teórica}

As circunstâncias atuais de crescimento do status da língua portuguesa no panorama mundial nos remete popularmente à ideia de globalização como processo internacional de integração e elemento propulsor dessa expansão. No entanto, essa é uma noção altamente discutida e contestada, principalmente no que concerne às políticas linguísticas (RIZVI; LINGARD, 2010). Uma das preocupações emergentes no ensino de línguas e, por conseguinte, deste trabalho é o debate sobre os benefícios e, principalmente, as duras consequências da globalização; entre elas estão o colonialismo, o eurocentrismo e a tensão entre a homogeneização e a heterogeneização política, cultural, social e linguística, pois "agora, mais do que nunca, os linguistas aplicados estão conscientes do papel desenvolvido pelo colonialismo na manutenção do domínio do ocidente na produção e disseminação do conhecimento" (KUMARAVADIVELU, 2006, p. 135).

Portanto, não somente entendo a globalização pelo viés do fenômeno econômico e mercadológico de ordem mundial, mas também como um evento que contribui incisivamente com as diversas transformações políticas, econômicas, culturais, sociais, e, dessa forma, linguísticas, perpetuando valores hegemônicos de poder, os quais são excludentes, injustos e que interferem diretamente nas nossas relações com os diferentes outros e com o imaginário social (RIZVI; LINGARD, 2010) das pessoas sobre o mundo em que estamos vivendo e construindo. Ou seja, a globalização permite que as pessoas naturalizem as condições que, ao contrário do que possam pensar, foram construídas ideologicamente para a manutenção da hierarquização verticalizada de poder e acesso. Por isso, partindo desse raciocínio, a globalização não afeta todo mundo da mesma forma. 
Sendo assim, corroborando com os mencionados autores, a globalização pode ser entendida como uma ideologia, posto que ela implica uma gama de normas e valores com status de privilégio, isto é, de hegemonia, a qual foi incorporada às maneiras como refletimos sobre a vida cotidiana, inserida em nossos sentimentos e cristalizada em verdades inquestionáveis ou notoriamente estáveis por diversos grupos de pessoas (RIZVI; LINGARD, 2010). Disso, advém a necessidade de questionarmos o status quo de discursos no movimento de desnaturalização de certezas e normalidades.

Ressalto, então, que a globalização, o colonialismo e o eurocentrismo não são concepções isoladas ou excludentes na contemporaneidade, pelo contrário, são interdependentes e buscam uma nas outras forças de consolidação e perpetuação para a sua lógica universalizante. No âmbito educacional e principalmente no ensino de línguas, elas estão diretamente imbricadas. Por isso, é imprescindível que respondamos a esse mundo globalizado com práticas que levem à problematização dos sentidos hierarquicamente construídos por essa premissa desintegradora. Como nos incita Kumaravadivelu (2010, p. 135), "ao preparar a sua disciplina acadêmica para enfrentar o mundo globalizado, aqueles que fazem LA têm uma responsabilidade especial porque, em grande parte, lidam com uma língua que têm tanto características globais como coloniais”. A língua portuguesa no Brasil, por sua história, não estaria fora dessa conjuntura.

Para o ensino de línguas, acredito que é necessário buscarmos discursos alternativos, práticas diferenciadas e subversivas capazes de ressignificar o que hoje é tido como axiomático no espaço transmoderno (CASTRO-GÓMEZ; GROSFOGUEL, 2007) de construção de conhecimentos. Interpreto esse espaço, em linhas gerais, como uma abertura a novos caminhos de experimentar o mundo, ou seja, a geração de alternativas para entender o que (achamos que) conhecemos ou desconhecemos.

Sendo assim, entendo que as perspectivas de ensinar língua/linguagem devem desenvolver esse pensamento, pois é com a linguagem e por meio dela que os mais diversos discursos dominantes são reproduzidos, mas que também podem ser repensados, pois, como afirmam Bernstein et al. (2015, p. 13, tradução minha), "a aprendizagem de uma língua dominante pode ser tanto opressiva e libertadora, empoderando ou oprimindo".

Em contrapartida aos efeitos homogeneizantes da globalização, uma das possíveis alternativas, como os autores parecem sugerir, é a educação como resistência, isto é, a educação como um novo par de óculos que nos possibilite rever o processo destrutivo e 
opressor da naturalização dos sentidos que nos rodeiam, o qual nos oportunize enxergar em direção oposta à visão genuína de conceber o mundo, pois são valores, conhecimentos e pessoas que são rotineiramente subjugados por essa estrutura. Vejo, portanto, no ensino de línguas essa possibilidade, compartilhando da ideia de Bernstein et al. (2015, p. 6, tradução minha) quando afirmam que "a educação de língua oferece a possibilidade de desenvolver as capacidades críticas dos nossos alunos como eles aprendem a ler o mundo e usam a linguagem para formá-lo e governá-lo”. Baseado nessa prerrogativa, encontro no ensino de língua um espaço de resistência e atuação a favor da justiça social.

Com esse intento, soma-se a importância da filosofia do LC. Partilhando das contribuições de Monte Mór (2013), Menezes de Souza (2011) e Duboc (2012, 2015), compreendo o LC como uma filosofia de vida - e por que não de ensino também? - que promulga o desenvolvimento da consciência crítica de maneira a problematizar as questões sociais, priorizando a heterogeneidade e a pluralidade de vozes e, com ela, a expansão de perspectivas (MONTE MÓR, 2012; DUBOC, 2012, 2015). Logo, o estudo da gramática da língua exerce um papel serviente (IFA, 2014) no propósito sociocomunicativo dos aprendentes. Portanto, o modificador crítico deve ser entendido desde uma perspectiva decolonialista (CASTRO-GÓMEZ; GROSFOGUEL, 2007; QUIJANO, 2007), isto é, como exercício de deslocamento e ruptura de pensamentos cristalizados, em que se abre espaço para a produção de novos e diferentes sentidos (MONTE MÓR, 2013), rechaçando a ideia de uma verdade absoluta e incontestável.

“Toda teoria crítica é histórica”, como já afirmou Kleiman (2013, p. 46). Segundo a autora, ao considerar uma teoria como crítica, está sendo concebido que os sujeitos carregam consigo "marcas de sua própria situação histórica" (KLEIMAN, loc. cit.) e, com isso, problematizam-se as categorias epistemológicas que buscam reatualizar "o pensamento dicotômico neutralizador" (KLEIMAN, loc. cit.), o qual tende a perpetuar uma lógica binária de exclusão. Ainda em diálogo com o que postula a autora, unindo-o à perspectiva deste trabalho, o LC busca, nesse sentido, não deixar à margem as histórias locais que definem e particularizam esses sujeitos. Portanto, segundo a autora, citando Castro-Gómez "uma das tarefas da teoria crítica no projeto da decolonialidade seria visibilizar novos mecanismos de produção das diferenças do mundo globalizado" (CASTRO-GÓMEZ, 2000 apud KLEIMAN, 2013, p. 48). 
No entanto, Menezes de Souza (2011) esclarece que a produção de significados não é um ato fortuito e arbitrário de indivíduos autônomos, senão um ato demasiado complexo que se desenvolve no social, na história e no coletivo, em que cada agente na formação de significados pertence simultaneamente a diversos e distintos grupos sociais. Nas palavras do autor, "existem sim fundamentos sobre os quais normas, verdades e ações éticas e políticas possam ser empenhadas; porém, esses fundamentos são vistos como contingentes e comunitários - não universais - e, portanto, temporais, locais e mutáveis” (MENEZES DE SOUZA, 2011, p. 137). Para isso, não só nos vale buscar entender a perspectiva do outro, mas, sobretudo, entender o porquê de nós estarmos entendendo como entendemos e as influências histórico-sociais dos significados que o outro e eu produzimos.

\section{Percurso Metodológico}

Metodologicamente, esta investigação possui uma abordagem qualitativointerpretativista, isto é, tem pressupostos divergentes do paradigma positivista. Não adoto, portanto, a pressuposição de que a realidade está dada e que a podemos conhecer de maneira absoluta por meio de um método específico ou de uma maneira independente em busca da verdade e legitimidade universais, imutáveis e aplicáveis. Tampouco atesta uma única e esgotável forma de interpretação dos dados.

Nesse sentido, a Linguística Aplicada, área em que se encontra este estudo, possui um arranjo diverso e heterogêneo, opondo-se à concepção de que só o pesquisador possui o saber privilegiado, logo, os participantes saem da categoria de coadjuvantes e constituemse protagonistas. Dessa maneira, os espaços institucionais de promoção do saber extrapolam a sala de aula convencional. Segundo Moita Lopes (1998, p. 108), "há, portanto, vários espaços sociais envolvidos com pesquisa fora da universidade ou cujos participantes têm conhecimento singular sobre a prática social na qual vivem". Portanto, o interesse do estudo está no problema, não em instituições.

Diante disso, optei pelo estudo de caso, conforme as perspectivas de Stake (1995) e Creswell (2014), dado que busquei investigar o caso Curso de Português para Estrangeiros (CPE), em 2015, uma realidade até então inexistente na Ufal em que foi realizada a pesquisa. Não objetivando, portanto, intervir com ações para uma mudança no ensino de PLA na universidade, os alunos participantes e eu buscamos construir conjuntamente essa 


\section{(Des-re)construindo espaços transgressores e conbecimentos nas aulas de PLA: retratos de uma experiência na Universidade Federal de Alagoas \\ Rusanil dos Santos Moreira Júnior}

experiência e, concomitantemente, por meio de descrições do processo de desenvolvimento das aulas levadas a cabo, procurei entender profunda e sistematicamente como os diferentes elementos constitutivos do CPE dialogaram e produziram os impactos analisados.

O curso de PLA teve uma roupagem diferente de cursos comuns porque, além de não propor uma sequenciação de grupos nivelados e não utilizar um livro didático para o planejamento e organização dos encontros, as aulas foram pautadas em temas livres de discussão que eram propostos pelos alunos e pelo professor-pesquisador, ou seja, o design das aulas era construído a cada encontro a partir das emergências sociais do grupo, no projeto CCC. Ao longo do curso, foram abordados 10 temas, entre eles Cidades urbanas (sexto tema), de onde os dados deste texto foram extraídos. Esse foi o primeiro tema abordado no período pós-greve ${ }^{3}$. Naquele momento, retornamos às aulas iniciadas em março de 2015 em outro ambiente escolar, bem diferente do que eles conviviam, uma vez que não foi possível continuar as aulas no campus da universidade no período de greve. Estávamos, então, no Centro da cidade de Maceió: longe da universidade, distante da zona privilegiada da capital, diferente dos shoppings centers com os que eu acreditava estarem acostumados, enfim, divergente do espaço onde todos os alunos moravam. Unindo essa ideia à da ampliação das perspectivas individual, local e global (MONTE MÓR, 2012) com as quais queria trabalhar, pareceu-me oportuna a sugestão do tema Cidades urbanas, cujo espaço onde continuaríamos as nossas aulas era convidativo.

O penúltimo encontro sobre esse tema consistiu em um passeio com fins pedagógicos na zona de comércio do Centro de Maceió a fim de coletar materiais para a atividade final sobre o tema. Eram fotos. As alunas participantes desta aula - universitárias não brasileiras - deveriam fotografar o que, para elas, representavam a cidade urbana. Tais fotografias foram postadas e legendadas a seu critério na nossa conta de Instagram @elportuguestoyou, que consistiu na nossa produção final sobre o tema. Para essa atividade, as alunas foram provocadas com a seguinte indagação: O que, para vocês, representa a cidade urbana? Nos três encontros precedentes, havíamos discutido esse tema. No último encontro de cinco no total, discutimos sobre as fotos postadas por elas.

\footnotetext{
${ }^{3}$ No ano de 2015, houve a greve nacional dos professores universitários que iniciou oficialmente no dia 28 de maio e se estendeu até o dia 13 de outubro do mesmo ano, com duração exata de 139 dias, ou seja, foram 5 (cinco) meses de paralisação das atividades acadêmicas, no entanto, retornamos às aulas do CPE um pouco antes da greve ter sido finalizada oficialmente.
} 
Nos dados analisados, estão presentes as alunas Raíssa, Sara, Camila e Isabel ${ }^{4}$. As três primeiras são estadunidenses de origens e localidades diferentes de seu país e a última é cubana. Todas as quatro estudantes chegaram ao curso com experiências e bagagem linguístico-discursiva totalmente diferentes de/em língua portuguesa. Sara, por exemplo, teve acesso a conhecimentos formais de/em língua portuguesa em seu país, contudo, Isabel relatou nunca haver estudado ou tido contato com a língua portuguesa em seu país; neste momento, então, estavam sendo construídas as suas primeiras experiências com a língua.

Consoante com o que assegura Creswell (2014), uma pesquisa qualitativa requer uma diversidade de dados buscando entender holisticamente o fenômeno estudado. Para isso, ao longo da pesquisa foram utilizados questionários iniciais, produções escritas, fotos e suas legendas, gravações em áudio das aulas, mensagens via WhatsApp, meus diários reflexivos, entrevistas semiestruturadas e questionários finais com o objetivo de entender a partir de uma gama de meios o processo das experiências vivenciadas.

No final do processo, em seguida a uma contínua revisita às bases teóricas, metodológicas e de dados, consegui organizar o que chamei de estudo linguístico-discursivo crítico de e em PLA. Neste texto, contemplo um recorte de um dos elementos constitutivos que compôs o mencionado estudo: a imprescindibilidade de ações transgressoras para a aprendizagem do PLA.

\section{Interpretação dos dados}

Conforme fomentei ao longo deste trabalho, uma possível resposta a uma educação que nos leve à problematização e a alternativas (CASTRO-GÓMEZ; GROSFOGUEL, 2007; MACIEL, 2014; MONTE MÓR, 2012), eu a vi em forma de práticas diferentes, atividades diferenciadas, iniciativas didáticas provocantes que ultrapassassem, se não o inesperado, o comum, por isso as nomeei de ações transgressoras. Em outras palavras, são práticas que se oponham às formas tradicionais e que sejam a favor de novas vias de conhecimento. Sendo assim, a idealização de sala de aula ultrapassa a visão tradicional do espaço físico de uma escola tal qual concebemos hoje e que acredito por ela termos crescido, ou seja, entendo que outros lugares podem se configurar uma sala de aula

\footnotetext{
${ }^{4}$ Todas as participantes, de nomes fictícios, assinaram o Termo de Consentimento Livre e Esclarecido (TCLE) do projeto de pesquisa submetido na Plataforma Brasil e aprovado pelo Comitê de Ética da Universidade Federal de Alagoas.
} 
quando se tornam ambientes de troca de saberes, de produção de conhecimentos, de ressignificação de sentidos e reflexão sobre eles e, neste caso, de estudo da língua viva (BAKHTIN/VOLOCHÍNOV, 2014), se tais ações forem planejadas com o fim na aprendizagem desestabilizadora e provocadora de sentidos.

A seguir, vejamos o resultado da atividade realizada na aula-passeio sobre as cidades urbanas. Entre todas as fotos, seleciono quatro a fim de análise que proporcionaram uma ampla e diferenciada discussão em sala de aula e revelaram indícios de LC e aprendizagem do PLA. As legendas se encontram reproduzidas abaixo das imagens tais quais foram criadas pelas alunas. Durante a análise, há transcrições de recortes das discussões sobre as fotografias, que também são objeto de análise.

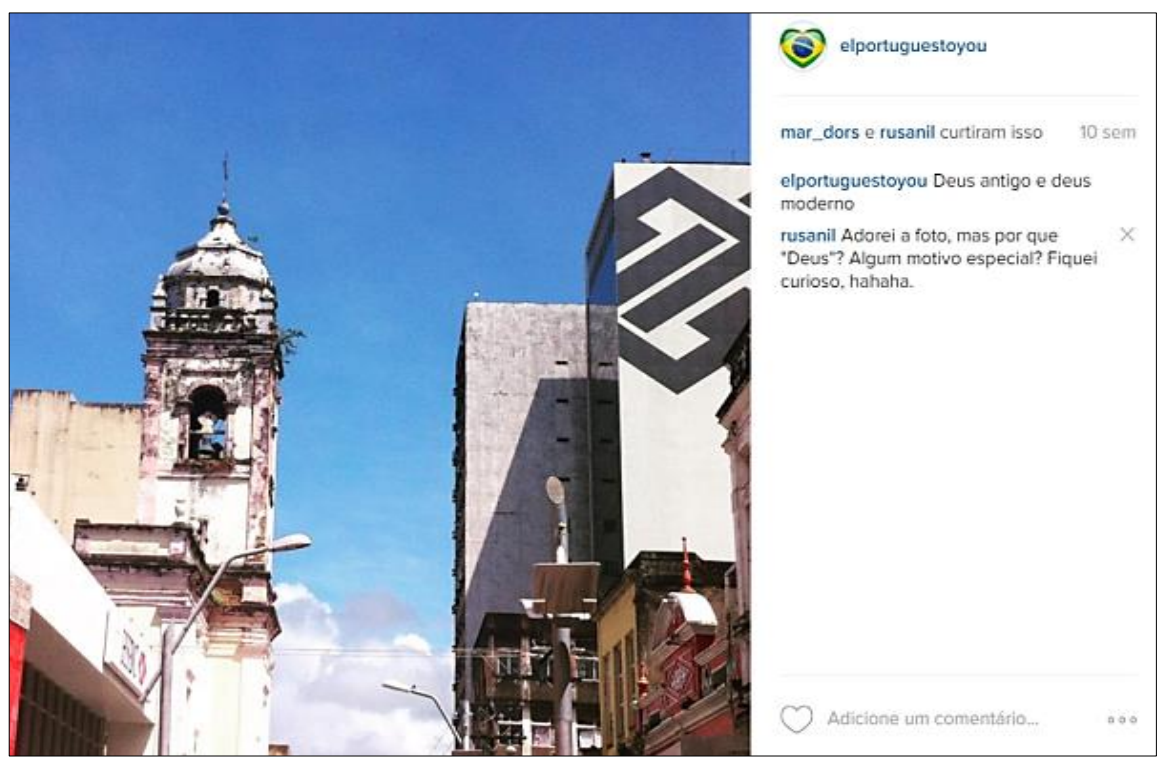

Fotografia 1: Deus antigo e deus moderno. Postagem de Raíssa no perfil de Instagram da turma.

$\mathrm{Na}$ fotografia 1, a aluna em sua legenda traz os adjetivos antigo e moderno para distinguir duas concepções que aparentemente não parecem ter o mesmo referente: o primeiro à igreja à esquerda e o segundo à instituição financeira à direita. Esse olhar singular dela despertou em mim a curiosidade - como se vê no comentário que realizo na publicação “Adorei a foto, mas por que "Deus"? Algum motivo especial? Fiquei curioso, hahaha.", como também despertou em Sara que, no encontro para as discussões, expressou "Eu também quando tava olhando no Instagram, eu vi essa foto e a legenda, eu fiquei curioso ${ }^{5}$ também, [...] ai

\footnotetext{
${ }^{5}$ Todo e qualquer desvio linguístico realizado pelos participantes será reproduzido na íntegra.
} 
fiquei pensando: no que será?" - em saber o que Raíssa havia pensado no momento da referida fotografia, fazendo-nos, depois da publicação, refletir sobre isso.

No encontro seguinte à nossa ida ao Centro da cidade, dia que dedicamos à discussão sobre as fotos publicadas, Raíssa poderia elucidar o que havia intencionado, bem como escutar o que os colegas pensaram ao ver o seu trabalho, contudo ela não esteve presente. Talvez essa situação fosse um ponto negativo para as nossas discussões, no entanto, busquei ver de maneira diferente. A ausência de Raíssa nos proporcionou atribuir sentidos às suas fotografias que ocasionalmente não haveria sido possível se ela nos dissesse em prontidão o que havia pensado.

Desse modo, buscamos rechaçar a interpretação certa que a autora da foto poderia nos provocar. Em lugar de uma interpretação verdadeira, dei espaço a indagações, a produções de novos sentidos, a caminhos alternativos, como foi provocado por mim em "Por que DEUS antigo e DEUS moderno'? Por que DEUS'? O que vocês imaginam?”. Nessa perspectiva, vejamos os seguintes excertos como respostas aos questionamentos:

- Para mim, a igreja que antes era o Deus que... as pessoas se dedicaram muito da vida à igreja e essas coisas; hoje em dia, é o banco porque todo mundo se dedica ao dinheiro $e$ a ascensão de crescer financialmente [...] (SARA - transcrição da gravação em áudio).

- Eu acho também, tipo, você tem essa ideia que "a Deus você pede muita coisa, você ora", né? E no banco você tá sempre pedindo dinheiro, préstimo, essas coisas hoje em dia (SARA - transcrição da gravação em áudio).

É possível perceber na fala de Sara - primeiro excerto - uma reflexão sobre os valores que damos importância na contemporaneidade, mas não somente esses. Ela faz um retrospecto histórico-social sobre a influência da instituição social igreja na maneira como as pessoas interagiam e se comportavam, comparando-a à incessante busca pelo progresso financeiro atualmente. Concebo esse posicionamento como crítica às relações globalizatórias e neoliberais (RIZVI; LINGARD, 2010; BERNSTEIN ET AL., 2015), atualmente de natureza capitalista, cujas políticas se fundamentam na discutível ideia de promover o bem-estar humano e a liberdade individual de forma homogeneizante, a qual intervém na formação ideológica das pessoas e, consequentemente, em seu imaginário social sobre como devemos viver em sociedade.

Por meio dessa perspectiva, é possível interpretar a foto como uma equiparação entre essas duas forças: a religiosa e a financeira nos dias atuais, como está representado na 
foto, uma de frente à outra. Imbricado a isso - no segundo excerto - ainda o relacionando à legenda da foto, Sara faz uma interpretação do porquê da palavra Deus, resgatando uma visão de que estamos sempre a pedir a alguém com mais poder (espiritual, financeiro, social), o que interpreto em sua fala como a necessidade do outro nas diferentes relações sociais as quais, independentemente da época, dos nossos interesses, das nossas práticas e do outro a que(m) se roga, esse outro não é apagado ou sucumbido.

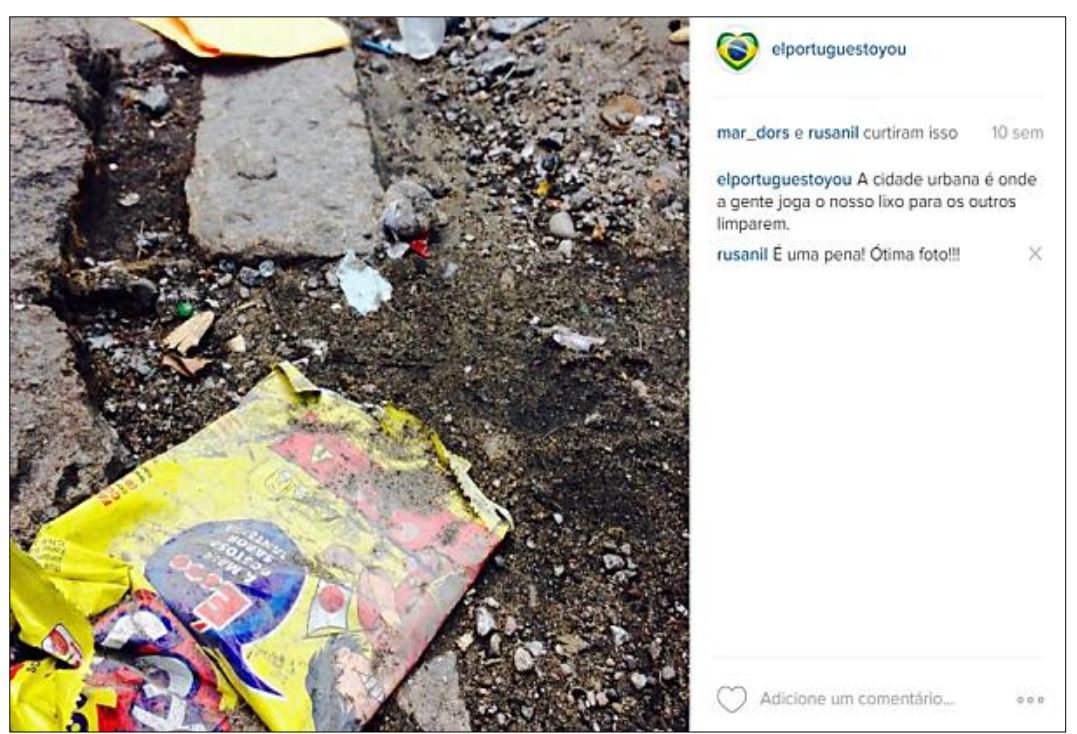

Fotografia 2: A cidade urbana é onde a gente joga o nosso lixo para os outros limparem. Postagem de Sara no perfil de Instagram da turma.

$\mathrm{Na}$ discussão sobre a fotografia 2, que tinha em pauta o indevido descarte do lixo, destaco três aspectos que me foram muito relevantes na problematização crítica sobre esse tema: a) a efetivação de políticas públicas, b) o aspecto cultural nas relações sociais e c) a quebra do ciclo de interpretação. No que se refere ao primeiro ponto, é discutida entre o grupo a existência de leis nos Estados Unidos e no Brasil as quais promovem a preservação do espaço público. No entanto, o que mais me chama a atenção está na fala de Camila: "Que não só pode ser o governo, a policial, você precisa outras pessoas que [...] cuidar um pouquinho". Nesse excerto, é perceptível uma visão que extrapola o senso comum de que o governo possui a inteira responsabilidade sobre o espaço público; tem-se, portanto, uma ideia de coletividade, de ação compartilhada, a qual é necessária para o bem-estar social. Esse pensamento me remete à discussão de Gallo (2016, p. 69) que, posicionando-se na perspectiva do filósofo francês Gilles Deleuze quando aborda o exercício de produção de multiplicidades, afirma que "não há sujeitos, não há objetos, não há ações centradas em um ou outro; [...] Todo projeto é coletivo. Todo valor é coletivo. Todo fracasso também”. Em 
outras palavras, é a coletividade, o agenciamento em conjunto que promovem transformações e deslocamentos, não pautados na individualidade.

Em relação ao segundo ponto, no excerto em que Camila afirma "acho que as pessoas [dos Estados Unidos] crescem pensando [em não poluir], eu acho que mais do que a multa é a vista das pessoas, não é visto tão bom. Se alguém vê você jogando lixo, vai achar 'Ah, essa pessoa não é educada, não cuida a nossa cidade...", destaco em sua fala a relevância do cultural intrínseca às nossas relações sociais, trazendo à luz a importância da educação. Esse ponto de vista se faz presente também na fala de Isabel "os meus meninos desde muito pequenino, eles têm hábito de não jogar lixo na rua, fora de lixeira, então eles não faz̧em" quando trata da educação permitida aos seus filhos.

Ainda nesse aspecto, saltou-me aos olhos a atenção que Camila deu aos garis. Não por eles serem de uma importância menor (e não são), mas por eu não ter cogitado essa discussão, por não ter pensado nesse outro, uma vez que, normalmente, quando se trata do tema poluição, a atenção é dada ao lixo e ao problema que ele causa pelas pessoas que o descartam indevidamente, mas não é comum pensar na atitude desrespeitosa às pessoas que trabalham fazendo a coleta desse lixo, ainda que o seu trabalho seja constituído por essa atividade. Vejamos o excerto da reflexão de Camila:

- Você acha que às vezes seria a falta de um respeito às... [aos garis]? [...] Os meninos [do Ensino Médio] falaram assim Eu posso jogar o lixo em qualquer lado porque a gente está pagando os empregados a limpar. Então, eu posso deixar assim, no chão, fora...' (CAMILA - transcrição da gravação em áudio).

Nesse excerto, interpreto em Camila uma atitude crítica de pensar o descarte indevido do lixo. A partir dessa visão, mais que sujar o ambiente, mais do que uma possível atitude inconveniente, também existe uma ação de desrespeito ao trabalho do outro, conjugada a uma visão mercadológica de que se suja porque há alguém destinado a realizar esse trabalho, o qual é remunerado para isso, logo é dever do gari limpar o ambiente e direito nosso sujá-lo. Essa perspectiva insensata de pensar o trabalho do gari negligencia, portanto, as concepções de preservação ambiental e de lugar comum e coletivo, o que parece ter sido assinalado no relato de Camila. "É cultural! Eu acho que é cultural' na fala dela e "Eu acho que o problema é educação. Cultural' dito por Isabel reforçam a ideia de que os pensamentos e ações irresponsáveis não são imanentes às pessoas, tampouco pertencentes a um povo, a um território ou a um conjunto hegemônico, mas sim a hábitos que sujeitos 
constroem, compartilham e que podem ser repensados, discutidos e revistados por meio de uma educação comprometida com a transformação social.

Em relação ao último ponto, a quebra do ciclo interpretativo, destaco duas passagens a fim de análise:

PASSAGEM 1 [transcrição da gravação em áudio]:

Camila: - E também porque aqui estamos no Centro, né? Porque na orla você não vai ver tanto.

Isabel: - Mas atención porque os meus filhos jogam todos os dias na praia e às vezes vêm meninos que, eles pensam que não são do barrio, por a forma de comportar-se, eles vêm com copos desechables? ("Ah, descartáveis", corrige o professor) eles... jogam na arena e queda todo sucio.

PASSAGEM 2 [transcrição da gravação em áudio]:

Sara: - Mas eu já morei no Equador, e também tinha muito lixo na rua.

Isabel: - Tem?

Sara: - Tem. Eu acho que assim: quando as pessoas que você conhece são da área acadêmica que geralmente vem de... não sempre, mas pelo menos têm mais educação...

Nesses dois excertos, vejo mais latente a tomada de ruptura de um binarismo ou de uma percepção comum de ver os lugares e atribuir-lhes características hegemônicas. $\mathrm{Na}$ primeira passagem, Camila parece justificar o centro da cidade como um lugar maltratado pelo lixo por ser uma área de menos prestígio ou atenção social, enquanto que a orla da cidade, numa posição inversa de valor, é beneficiada e, assim, mais bem cuidada. No entanto, Isabel desconstrói essa ideia, dizendo que na orla também há sujeira, e que não é algo esporádico, mas algo a que vem sendo assistido “todos os dias na praia”. Para isso, ela dá exemplo da experiência de seu filho e também já adianta o questionamento que poderia surgir de que a sujeira é deixada por aqueles que não são do ambiente maltratado em "eles [os filhos de Isabel] pensam que [as pessoas que jogam lixo] não são do barrio por a forma de comportarse”, deixando a entender o contrário, isto é, são os próprios moradores do bairro que poluem o espaço. Apesar de não transparecer na transcrição, no momento da aula, considerando os elementos não linguísticos como a entonação da fala, Isabel dá indícios de que essas pessoas com esse tipo de atitude são habitantes do próprio bairro nobre onde se encontra a orla.

A segunda passagem decorre da incitação de Isabel ao afirmar que os latinoamericanos que havia conhecido em seu país eram pessoas conscientes do descarte do lixo, que tinha um comportamento adequado, ao contrário dos seus conterrâneos, os cubanos. Vejamos que, enquanto na primeira passagem a Isabel descontrói a visão de Camila mostrando outra perspectiva, na segunda, é a posição de Isabel que é desconstruída por 
Sara a qual, por sua vez, mostra-lhe uma outra visão a partir de suas experiências de quando residiu no Equador, país latino-americano. A perspectiva de Sara, inclusive, parece surpreender Isabel durante o diálogo, perceptível mediante a sua interrogação "Tem?" quando Sara afirma que no Equador há muito lixo nas ruas.

A partir desses casos de LC nas passagens 1 e 2, está claro que todos nós estamos dispostos a reproduzir discursos homogeneizadores, conscientes ou não deles. Ninguém está imune a isso, pois somos constituídos em meio a esses discursos. Contudo, é possível problematizar outros que nos saltam aos olhos, ressignificar nossos posicionamentos e talvez possibilitar esse redesign (JANKS, 2016) a outrem. Como as passagens exemplificaram, ora Isabel questionava criticamente, ora ela era questionada criticamente. Esses exemplos rompem com a idealização da velha emancipação constituída pelo emancipador (o professor) e pelo emancipado (o aluno) em posições determinadas e pactuadas. Reavaliar-se é uma construção coletiva e dialógica. É emancipar-se.

Embora Sara tenha trazido à discussão um outro olhar sobre o que Isabel havia opinado, Sara não desvalida a percepção de sua colega, mas resgata o contexto históricosocial das pessoas citadas por Isabel. Por serem acadêmicas, essas pessoas possuem características que lhe proporcionam uma visão mais consciente, o que não é regra. Vejo, então, por parte de Sara, mais uma tentativa não homogeneizadora de relacionar um povo, um território, uma língua E uma maneira de pensar.

Notadamente, não apenas a sensibilidade crítica $^{6}$ das alunas foi trabalhada: vê-se ao longo das produções escritas e orais um aprimoramento linguístico-discursivo das participantes. Através de um trabalho pautado no LC, a aprendizagem da língua portuguesa não foi negligenciada, tampouco marginalizada. À medida que discutíamos questões sociais, o estudo da linguagem/língua era trazido a reboque, recusando a artificialidade, uma vez que o estudo de uma língua, seja materna ou seja adicional, não deve se desvencilhar do tratamento linguístico-discursivo, pois acredito que é por meio do LC que podemos questionar o mundo e, ao fazê-lo, redimensionar a língua que utilizamos para nele atuar. Nesse sentido, destaco paulatinamente três passagens (3, 4 e 5) que sinalizam uma abordagem linguístico-discursiva.

\footnotetext{
${ }^{6}$ Ao adjetivar sensibilidade, entendo-a não só como a capacidade de sentir e perceber o mundo por meio dos sentidos e linguagens. Extrapolo esse entendimento. Concebo-a como um pensar, um exercício de reflexão sobre esse sentir, o qual propõe a interrogação de dizeres, de ações.
} 
PASSAGEM 3 [transcrição da gravação em áudio]

Professor: - Aí eu pergunto a vocês: eles protegem o quê de quem?

Camila: - Eu suponho o dinheiro de... dos pobres.

Professor: - É o dinheiro DOS pobres? Você...

Camila: - Na, na, não. Está protegendo o dinheiro dos... bom, dos bancos, e não querem que os ladrões, os pobres se roubam...

Sara: - Como é que você fala... porque "não é o dinheiro dos pobres"...

$[\ldots]$

Isabel: - Não é contra os pobres, é contra os bandidos.

$\mathrm{Na}$ terceira passagem, o uso das preposições de e contra incide diretamente no sentido que Camila quer expressar. Sara, notando a dificuldade de Camila, que parece ser a sua também, objetivamente traz a relevo essa inquietação e demonstra o porquê da importância desse conhecimento na concepção do sentido provocado "Como é que você fala... porque não é 'o dinheiro dos pobres'”. Logo em seguida, vemos que essa brecha de tratamento estrutural e semântico da língua não prejudica a discussão, pelo contrário, fortifica-a, como fez Isabel. Ela não só retoma o uso adequado da preposição que foi esclarecido, mas também o problematiza para a discussão que foi provocada "Não é contra os pobres, é contra os bandidos". Assim, o tratamento linguístico-discursivo situado não só foi necessário como também complexificado na discussão.

PASSAGEM 4 [transcrição da gravação em áudio]:

Professor: - A próxima imagem é essa aqui. A legenda é: "Que tal seduzir em Brasil? Um: ser Branco. Dois: ser magro. Três: ir para a Disney".

Sara: - Seria seduzir NO Brasil...

Professor: - "No Brasil", aham, porque EM se utiliza com cidades, não é? "Em Nova Iorque", "em Nova Jérsey", não é? Então, o que vocês acham dessa imagem? $[\cdots]$

Na passagem acima, Sara traz logo a priori o uso inadequado da preposição feito pela sua colega na legenda da foto. $\mathrm{Na}$ tentativa de esclarecer a ela e a todos o seu uso, rapidamente, explico o que motiva ou não a contração entre a preposição e o artigo sem exaustão, mas com a devida atenção ao comentário da aluna. Logo após, retornamos à discussão.

Penso que as ponderações, sejam elas de ordem gramatical ou não, realizadas pelos alunos não devem ser desconsideradas, pois acredito que quando as fazem, é porque há uma necessidade de verificação de um conhecimento que lhes é significativo para a construção de pontes de conhecimento. No entanto, sem a pretensão de querer esgotá-lo ou dar ao problema linguístico-discursivo uma atenção primária, como tentei fazer.

\footnotetext{
${ }^{7}$ Conversa sobre a fotografia 3 . Ver anexos.

${ }^{8}$ Conversa sobre a fotografia 4 . Ver anexos.
} 
Entendo que uma dúvida, por mais frívola que possa parecer, pode desencadear nos outros colegas o desemaranhamento de questões que eram de seu desconhecimento ou que não as tinham muito claras.

PASSAGEM 5 [transcrição da gravação em áudio]":

Sara: - E eu já vi algumas pessoas que usam um traje laranja...

Professor: - Unhum... uma roupa laranja? Ah, são os garis!

Sara: - Eles limpam, né?

[...]

Camila: - Unbum. Por exemplo, quando eu estava no ensino médio, sempre os meninos falavam assim: "Oh, eu posso jogar o copo aqui porque os..." Pode escrever a palavra? (Referindo-se a gari).

[...]

Camila: -- Então, os meninos falaram assim "Eu posso jogar o lixo em qualquer lado porque a gente está pagando os empregados a limpar. Então, eu posso deixar assim, no chão, fora...”. Você acha que isso aqui também?

Nessa passagem, o grupo pôde conhecer a palavra gari para se referir ao profissional que recolhe o lixo nas ruas. Além disso, pudemos entender que essa palavra não é dada a qualquer profissional que faz esse tipo de trabalho. Ressalto, assim, a importância do contexto, da situação vivida para a construção de sentidos. Ampliamos, portanto, a discussão. No primeiro momento, Sara se referia ao profissional que coleta lixo nas vias públicas. Depois, Camila já se referia ao profissional de serviços gerais que trabalha em instituições públicas ou privadas. São situações distintas, contextos diferentes, mas uma dúvida pertinente. Diante dessa necessidade, começamos a estudar as palavras usadas para designar ao responsável que realiza o serviço de limpeza (gari, empregado, rapaz/moça dos serviços gerais, secretária do lar, rapaz/moça da limpeza foram alguma delas), como também exploramos o valor social instituído a cada uma delas. Depois dessa breve discussão, Camila pôde usar a palavra que acreditou melhor expressar o que pretendia "Então, os meninos falaram assim 'Eu posso jogar o lixo em qualquer lado porque a gente está pagando os empregados a limpar...". Nesse momento, Camila teve a opção de escolher o signo linguístico (BAKHTIN/VOLOCHÍNOV, 2014), depois de compreendida a ideologia circulante em cada uma delas, que melhor representava o que quisera expressar.

Nas três últimas passagens acima abordadas (de 3 a 5), nota-se claramente um ganho linguístico-discursivo nas discussões propostas. Vale ressaltar que esse aprimoramento não é especificamente vocabular-lexical como se possa imaginar, mas, sim, de diversas naturezas que compõem a composição de uma língua viva e que diretamente se relacionam com o real, ou seja, com uma necessidade concreta, situada e que compromete

\footnotetext{
${ }^{9}$ Conversa sobre a fotografia 2.
} 
a geração de sentidos envolvidos nas interações. Ao responder uma das questões do questionário final, Sara evidencia o quanto a aula no centro da cidade, a sua preferida, conseguiu contemplar a língua ao vivo e, por meio do LC, ver com outros olhos o que comumente não tem a nossa atenção. Além disso, a aula que acredita mais ter aprendido foi aquela que, entre outras características que foram resgatadas nas análises, fugiu da concepção tradicional de aprender uma língua: estudar conteúdos linguísticos desconectados ou distantes da prática viva da língua, enclausurados em uma sala de aula comum. Ou seja, pudemos criar novos problemas e gerar novos encaminhamentos às situações que vivenciamos.

A aula em que mais aprendi sobre o tema trabalhado foi as cidades urbanas. Eu achei o texto muito interessante e aplicou a minha realidade no Brasil. Também, gostei do vocabulário que a gente aprendeu através do jogo de memória. [...] $A$ atividade que mais gostei de realizar foi tirar fotos no centro porque vi o vocabulário da aula ao vivo. Também, parei para ver e sentir coisas para que muitas vezees não tenho tempo (SARA - questionário final).

\section{Considerações finais}

Como contemporâneos professores de línguas, o tratamento de cultura(s) não pode - e nunca deveria - estar desprendido do ensino, pois o conteúdo cultural e ideológico lhe é inerente, não transcendente (BAKHTIN/VOLOCHÍNOV, 2014). Por isso, faz-se necessária uma postura crítica em sala de aula, isto é, em que promulguemos um espaço de compartilhamento de experiências, no qual efetivamente viabilizemos oportunidades e proporcionemos diversas possibilidades de interpretação e compreensão do mundo.

A sala de aula, portanto, deve ser um espaço de (des-re)construção em que novas maneiras de ensinar-e-aprender sejam fomentadas, ressignificadas e revisitadas, aproximando-a às emergências dos aprendentes. Sair do lugar comum pode ser abundantemente exitoso fora do ambiente tradicional da sala de aula, não com o objetivo de distrair os alunos e dispersá-los em meio à eloquência do vaivém do cotidiano, senão aproximar aos seus olhos o que talvez lhes seja difícil ver ou entender sentado em frente a um quadro negro em uma sala branca, onde toda a incompreensão do mundo parecer ser, como se consolida na linguagem popular, preto no branco, isto é, claro e simples. No entanto, há uma imensidão de cores e tons que podem ser distinguidos, alinhavados e recombinados. Nessa perspectiva, está o primor de planejamento compromissado com a 
promoção e desenvolvimento da consciência crítica em que a aprendizagem dos conhecimentos linguístico-discursivos não seja marginal ou secundária, mas que esteja, portanto, em diálogo harmonioso com o LC.

$\mathrm{Na}$ atividade proposta na aula-passeio, à primeira vista, constata-se que as alunas retrataram diferentes aspectos da cidade urbana, tema proposto para as fotos, com um olhar singular, crítico, as quais refletem enfoques que foram contemplados durante as discussões nos encontros sala de aula e outros que foram provocados posteriormente, como constatam os trechos da aula transcritos.

Como também é perceptível nas fotos, juntamente com os excertos das transcrições, a representatividade da cidade urbana ultrapassou o genérico, isto é, a percepção dela como oposição à cidade rural, aquela com peculiares prédios, veículos modernos e motorizados e tecnologia abundante. Acima disso, vê-se principalmente a preocupação com os valores que damos ao que nos cerca e ao que nos compõe como cidadãos. Valores esses que por vezes nos passam despercebidos, tornando-se comuns ou naturais.

Por fim, destaco a importância de que reforcemos nas aulas de línguas a necessidade de ampliar e/ou questionar olhares sobre o que nos rodeia e, consequentemente, que não sejamos omissos à heterogeneidade, à diversidade e à pluralidade que estão tão presentes nas sociedades, ultrapassando fronteiras não só territoriais, mas de perspectivas pessoais, comunitárias e globais (MONTE MÓR, 2010, 2012).

\section{Referências}

BAKHTIN, M. (VOLOCHÍNOV, V.). Marxismo e filosofia da linguagem: problemas fundamentais do método sociológico na ciência da linguagem. 16 ed. Trad. Michel Lahud e Yara Frateschi Vieira. São Paulo: Hucitec, 2014.

BERNSTEIN, K. A.; KATZNELSON, N.; VINALL, K. et al. Critical perspectives on neoliberalism in second/foreign language education. L2 Journal, California, v. 7, $\mathrm{n}^{\mathrm{o}} 3$, 2015, p. 3-14.

CASTRO-GÓMEZ, S.; GROSFOGUEL, R. Giro decolonial, teoría crítica y pensamiento heterárquico. In: El giro decolonial: reflexiones para una diversidad epistémica más allá del capitalismo global. Bogotá: Siglo del Hombre Editores; Universidad Central, Instituto de Estudios Sociales Contemporáneos y Pontificia Universidad Javeriana, Instituto Pensar, 2007. 
CRESWELL, J. W. Investigação qualitativa e projeto de pesquisa: escolhendo entre cinco abordagens. 3 ed. Trad. Sandra Mallmann da Rosa. Porto Alegre: Penso, 2014.

DUBOC, A. P. M. Epistemologias do tempo atual e a formação do professor de inglês. In: Atitude curricular: letramentos críticos nas brechas da formação de professores de inglês. Tese (Doutorado em Estudos Linguísticos e Literários em Inglês). São Paulo: Universidade de São Paulo, 2012, p. 73-96.

. Letramento crítico nas brechas da sala de línguas estrangeiras. In: MACIEL, R. F.; TAKAKI, N. H. (Org.). Letramentos em terra de Paulo Freire. 2 ed. Campinas: Pontes Editores, 2015.

GALLO, S. Deleuze \& a educação. 3 ed. Belo Horizonte: Autêntica Editora, 2016.

GIL, A. C. Didática do ensino superior. São Paulo: Atlas, 2009.

IFA, S. Reflexões sobre a formação de professores e novos letramentos no projeto de extensão Casas de Cultura no Campus da Universidade Federal de Alagoas. In: ZACCHI, V. J.; STELLA, P. R. (Org.). Novos letramentos, formação de professores e ensino de língua inglesa. Maceió: Edufal, 2014.

JANKS, H. Panorama sobre letramento crítico. In: JESUS, D. M.; CARBONIERI, D. (Org.). Práticas de multiletramentos e letramento crítico: outros sentidos para a sala de aula de línguas. Campinas: Pontes, 2016.

KLEIMAN, A. B. Agenda de pesquisa e ação em linguística aplicada: problematizações. In: MOITA LOPES, L. P. (Org.). Linguística aplicada na modernidade recente. São Paulo: Parábola Editorial, 2013.

KUMARAVADIVELU, B. A Linguística Aplicada na era da globalização. In: MOITA LOPES, L. P. (Org.). Por uma Linguística Aplicada indisciplinar. São Paulo: Parábola Editorial, 2006.

MACIEL, R. F. "Eu sei o que é bom pra você!". A lógica da emancipação revisitada e a formação de professores. In: ZACCHI, V. J.; STELLA, P. R. (Org.). Novos letramentos, formação de professores e ensino de língua inglesa. Maceió: Edufal, 2014.

MENEZES DE SOUZA, L. M. T. Para uma redefinição de letramento crítico: conflito e produção de significação. In: MACIEL, R. F.; ARAÚJO, V. A. (Org.). Formação de professores de línguas: ampliando perspectivas. Jundiaí: Paço Editorial, 2011, p. 128 140 .

MOITA LOPES, L. P. A transdisciplinaridade é possível em linguística aplicada? In: SIGNORINI, I.; MARILDA, C. (Org.). Linguística aplicada e transdisciplinaridade: questões e perspectivas. Campinas: Mercado de Letras, 1998.

MONTE MÓR, W. O ensino de línguas estrangeiras e a perspectiva dos letramentos. In: BARROS, C. S.; COSTA, E. G. M. (Org.). Se hace camino al andar: reflexões em torno do ensino de espanhol na escola. Belo Horizonte: Faculdade de Letras da UFMG, 2012, p. $37-50$. 
Crítica e letramentos críticos: reflexões preliminares. In: HILSDORF ROCHA, C.; MACIEL, R. F. (Org.). Língua estrangeira e formação cidadã: por entre discursos e práticas. Campinas: Pontes Editores, 2013, p. 31-50.

PENNYCOOK, A. Uma linguística aplicada transgressiva. In: MOITA LOPES, L. P. (Org.). Por uma Linguística Aplicada indisciplinar. São Paulo: Parábola Editorial, 2006.

QUIJANO, A. Colonialidad del poder y clasificación social. In: CASTRO-GÓMEZ, S.; GROSFOGUEL, R. El giro decolonial: reflexiones para una diversidad epistémica más allá del capitalismo global. Bogotá: Siglo del Hombre Editores; Universidad Central, Instituto de Estudios Sociales Contemporáneos y Pontificia Universidad Javeriana, Instituto Pensar, 2007.

RIZVI, F.; LINGARD, B. Perspectives on globalization. In: Globalizing education policy. New York: Routledge, 2010.

STAKE, R. The art of case study research. Thousand Oaks: Sage, 1995. 


\section{Abstract}

According to Bakbtin/Volochinov (2014), language, as an ideological product, reflects and refracts the reality that is external to it. Based on this assumption, the purpose of this article is presenting analyses of the discussions about four photos students took whose lesson focus was on urban cities. The photographs were taken during a Portuguese as an Additional Language (PLA) class trip in the city center of Maceio, in Alagoas. To that end, I adopted as theoretical contribution the studies on Critical Literacy MONTE MÓR, 2012; MENEZES DE SOUZA, 2011; JANKS, 2016) and the contemporary theories on globalization and its effects (RIZVI; LINGARD, 2010; CASTRO-GÓMEZ; GROSFOGUEL, 2007). Methodologically, I consider this research as a case study, in a qualitativeinterpretative perspective of research in applied linguistics. As a result, the analysis demonstrates a critical posture of the participants in relation to the daily practices who are rarely questioned and indicate a relevant improvement on their linguistic-discursive skills.

Keywords: Photographs. Urban cities. Critical literacy. Portuguese as an additional language. Globalization

Recebido em: 05/12/2017.

Aceito em: 16/05/2018. 
(Des-re)construindo espaços transgressores e conbecimentos nas aulas de PLA: retratos de uma experiência na Universidade Federal de Alagoas

Anexo 1 - Quem disse que o Brasil não é seguro? Postagem de Raíssa no perfil de Instagram da turma.

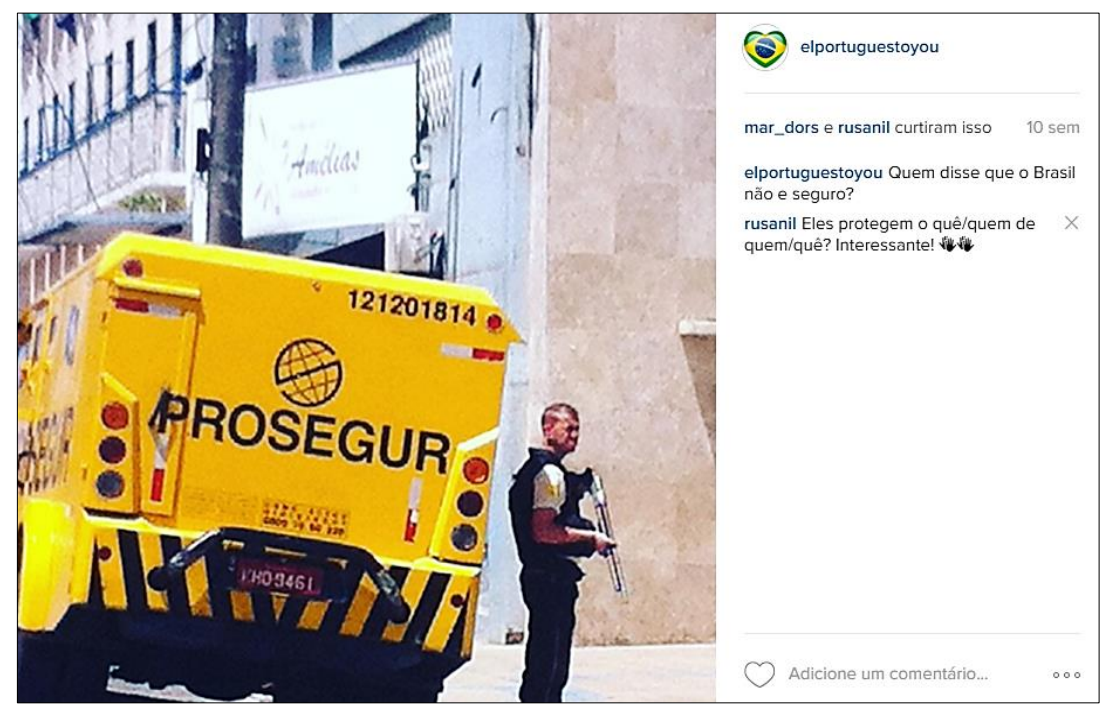

Anexo 2 - Que tal seduzir em Brasil? 1. Ser branco 2. Ser magro 3. Ir para a Disney. Postagem de Raísse no perfil de Instagram da turma.

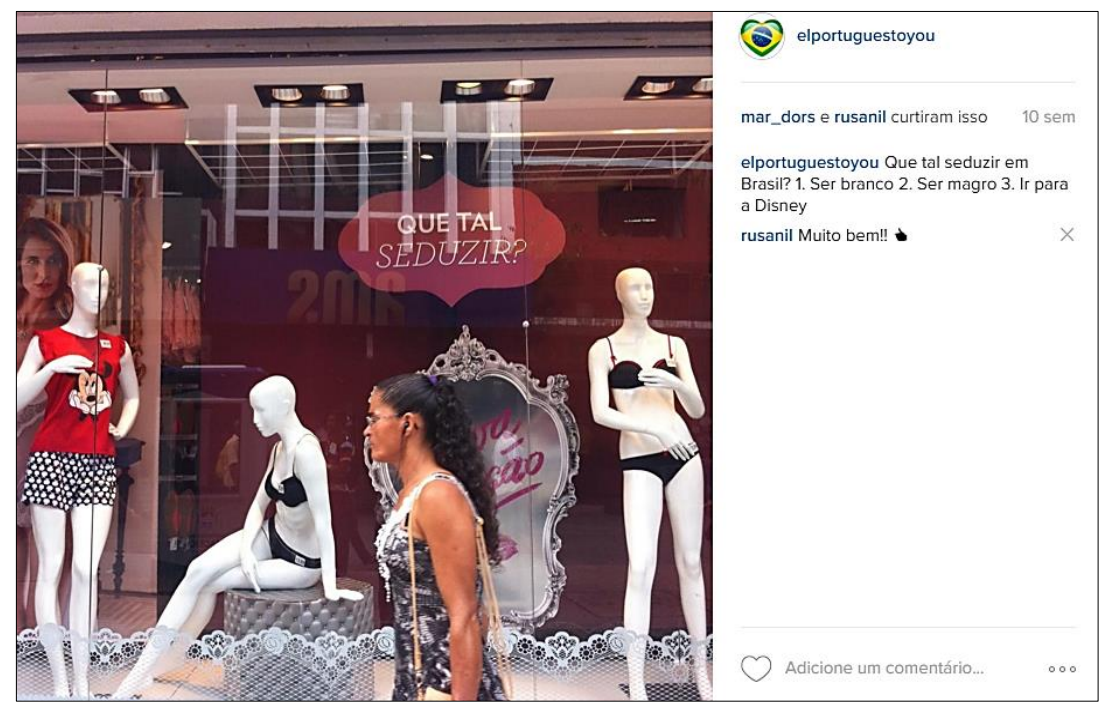

